\title{
Contribuição da Gestão de Operações para a Internacionalização de Empresas
}

\author{
Ely Laureano Paiva \\ Astor Eugênio Hexsel
}

\begin{abstract}
Resumo
Mercados internacionais têm sido um desafio para empresas brasileiras. Este artigo, com base em múltiplos estudos de caso, avalia o processo de inserção internacional, utilizando o enfoque da gestão de operações. Discutem-se as decisões tomadas ao longo da cadeia de valor de operações, CVO, seguindo uma lógica de estágios e de escolhas estratégicas. Inicialmente, os casos indicam diferentes decisões ao longo da CVO das empresas pesquisadas, considerando diferentes níveis de inserção no mercado internacional. Essas decisões compreendem as atividades de suprimento, pesquisa e desenvolvimento de produtos, $\mathrm{P} \& \mathrm{D}$, produção, distribuição e serviços agregados. O estudo sugere que nos estágios iniciais as ações são centradas nas atividades de distribuição e serviços e há uma orientação preferencial pela aprendizagem. Por outro lado, em estágios mais avançados, as decisões tomadas ao longo da CVO indicam que escolhas estratégicas levariam à expansão geográfica das atividades nos mercados internacionais.
\end{abstract}

Palavras-chave: estratégia de operações; internacionalização; cadeia de valor.

\begin{abstract}
International markets have been a challenge for Brazilian companies. This article analyzes the process of entrance in international markets from an operations-based perspective based on multiple case studies. We discuss the decisions that take place along the operations value chain (OVC), following stage and strategic choice logics. The cases indicate different decisions in the OVC's activities, according to the company's insertion in international markets. The OVC's activities ranges supply, $R \& D$, manufacturing, distribution and services. The results suggest that learning is the first objective for companies in the initial stages of internationalization. On the other hand, there are evidences that the geographic expansion of international activities is based on strategic choices along the OVC, when companies are in the most advanced stages of internationalization.
\end{abstract}

Key words: operations strategy; international business; value chain. 


\section{INTRODUÇÃO}

As pressões crescentes sobre o mercado doméstico brasileiro resultam de tarifas de importação decrescentes, investimentos estrangeiros e participação em acordos econômicos regionais. $\mathrm{O}$ foco brasileiro no mercado doméstico tem sido destacado tanto por publicações empresariais (THE ECONOMIST, 2000; EXAME, 2001) como por acadêmicas (BARTLETT; GHOSHAL, 2000). Nessas, alguns executivos declaram que, mesmo com a estabilidade econômica brasileira, mercados externos podem manter as receitas mais estáveis, sem as fortes oscilações causadas por fatores internos.

Entretanto, o início do processo de internacionalização é um desafio para empresas brasileiras. Defasagem tecnológica, escala e desconhecimento sobre mercados internacionais são fatores que ainda dificultam as ações de internacionalização de empresas brasileiras.

A fim de lançar luzes sobre o assunto, este artigo aborda o tema de internacionalização, seguindo dois enfoques: como processo de aprendizagem e como escolhas racionais (MELIN, 1992).

Dois aspectos são centrais, quando analisamos as decisões referentes à gestão de operações: configuração e coordenação (PORTER, 1986a). Configuração refere-se à distribuição geográfica das operações e às razões relacionadas à escolha da empresa. Coordenação refere-se a como as operações globais são coordenadas e ao grau de concentração de seu processo de gestão.

A complexidade do processo de internacionalização é discutida por meio das atividades da cadeia de valor e das possíveis decisões tomadas durante o processo de internacionalização.

\section{Escolas de Internacionalização de Empresas}

Pode-se identificar diferentes abordagens para análise de empresas que atuam em contextos internacionais, salientando-se, entretanto, duas grandes orientações (MELIN, 1992).

A primeira abordagem, que se articula a partir do trabalho de Johanson e Vahlne (1977), analisa a internacionalização como processo de aprendizagem que se 
desenvolve segundo diversos estágios, a denominada Escola de Uppsala. Esse enfoque com contribuições adicionais feitas por diversos estudiosos, especialmente dos países escandinavos, vem a ser conhecido mais tarde como Escola Nórdica (HILAL; HEMAIS, 2001). Os estudos dessa escola consideram, caso a caso, a estratégia de entrada de uma empresa em outro país.

A segunda abordagem discute especialmente as decisões de empresas multinacionais e considera o efeito conjunto de seus investimentos em diversos mercados nacionais. Nesse caso, a internacionalização é vista como o resultado de decisões racionais a partir dos objetivos da corporação e de diversas condições ambientais, sendo conhecida como paradigma eclético (ANDERSON; GATIGON, 1986; DUNNING, 1988).

Segundo a Escola Nórdica, a internacionalização ocorre como processo em que se destaca uma seqüência de etapas, do início das atividades de exportação até a instalação de plantas industriais no exterior. A lógica desse comportamento decorre da necessidade de gradual aquisição, integração e uso de conhecimento sobre os mercados e as operações no exterior e, ainda, do aumento do comprometimento com os negócios internacionais. A aprendizagem, que resulta desse processo de experimentação, é necessária para superar as distâncias psíquicas entre a empresa e os diversos mercados, em termos de língua, cultura, nível educacional, práticas de gerenciamento e legislação. Mais recentemente, Björkman e Forgsgren (2000) destacam a importância de as empresas inseriremse nas redes que se formam nos mercados globais para incrementar a aprendizagem e expandir os seus negócios internacionalmente.

Dentro de uma lógica de estágios de internacionalização, Andersen (1993) identifica quatro possibilidades:

. Estágio 1: Sem atividades de exportação regular;

. Estágio 2: Exportação por intermédio de representantes (agentes);

. Estágio 3: Estabelecimento de uma subsidiária no exterior;

. Estágio 4: Instalação no exterior de unidade de produção, podendo ser própria, resultante de licenciamento ou de arranjos sob forma de joint ventures.

Os conceitos propostos pela Escola Nórdica têm sido criticado por diversos aspectos (MELIN, 1992). Na medida em que eles se referem a uma única empresa entrando em um único país, eles não explicariam o efeito conjunto das posições das empresas multinacionais que atuam em diversos mercados geográficos. A proposta seria também muito determinista, por pressupor que as etapas de entrada ocorram de forma seqüencial, ignorando outras opções de escolhas estratégicas, 
como, por exemplo, iniciar a produção em outro país sem ter instalado uma filial de vendas nesse mercado.

Essas objeções, entretanto, não invalidam o valor dessa proposta. Ela é importante para entender as etapas iniciais da internacionalização que antecedem a instalação de uma unidade de produção no exterior. Além disso, permanece a idéia central do conceito, que destaca a importância da aprendizagem e da experiência acumulada para a expansão dos negócios internacionalmente, sem depender do tipo de decisões tomadas e da fase de internacionalização da empresa.

O paradigma eclético discute especialmente o problema da instalação de unidades de negócio em outros países, enfrentado por empresas multinacionais (ANDERSON; GATIGON, 1986; DUNNING, 1988). Ele se baseia na teoria econômica e considera as decisões de investimentos diretos em outros países como uma questão de escolhas racionais (BARRETO, 2002; KUTSCHKER; BÄURLE, 1997).

Hill et al. (1990) consideram que existem três alternativas para instalar empresas em outros países: o licenciamento, a associação sob forma de joint venture e unidades de negócios totalmente controladas pelo investidor. O processo de escolha entre as três opções deveria ocorrer com base no controle desejado, nos recursos a serem comprometidos e na avaliação do risco de o conhecimento tecnológico da empresa ser disseminado. Se uma empresa entrar com base em licenciamento, o controle e o comprometimento serão menores; porém o risco de se difundir o conhecimento da empresa será maior. A entrada, com base em unidade totalmente controlada pela empresa, resulta em maior controle e menor risco de difusão das habilidades da empresa; entretanto mais recursos terão que ser comprometidos. A posição representada por associação sob forma de joint venture implica uma posição intermediária entre os dois extremos citados.

Para a determinação das alternativas de entrada é preciso considerar também os objetivos da empresa quanto a seguir uma estratégia multidoméstica, em que os produtos e ações de marketing são diferentes para os diversos mercados ou uma estratégia global, quando a oferta tende a ser padronizada (PORTER, 1986a). Segundo Hill et al. (1990), uma estratégia multidoméstica favorece o licenciamento e a joint venture por implicar custos menores. Essa situação tem determinado políticas específicas quanto ao número de unidades, tipo de produto e componente a ser produzido em cada unidade e a localização dessas unidades. Em muitos casos, a empresa tem preferido a centralização da produção, como nas indústrias aeroespacial, de relógios e de equipamentos pesados. 


\section{Gestão da Cadeia de Valor de Operações e Estágios de Internacionalização}

Inicialmente, Porter (1986b) desenvolveu a noção de cadeia de valor, identificando atividades primárias e secundárias. De Toni e Forza (1992) adaptaram essa proposta para a gestão de operações numa visão de internacionalização, propondo a cadeia de valor de operações, CVO. As diferenças principais são a inclusão da pesquisa e desenvolvimento de produtos, $\mathrm{P} \& \mathrm{D}$, como uma atividade primária e a exclusão das atividades de marketing e vendas, pois os autores consideram essa atividade não está sob responsabilidade da gestão de operações (Figura 1).

\section{Figura 1: Cadeia de Valor de Operações}

\begin{tabular}{|c|c|c|c|c|}
\hline \multicolumn{5}{|c|}{ Critérios Competitivos } \\
\hline$\square$ & 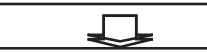 & $\square$ & $\square$ & 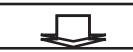 \\
\hline \multicolumn{5}{|c|}{ Sistemas Gerenciais e Tecnologia } \\
\hline$P \& D$ & $\begin{array}{l}\text { Logística de } \\
\text { Fornecimento }\end{array}$ & Produção & $\begin{array}{l}\text { Logística de } \\
\text { Distribuição }\end{array}$ & Serviços \\
\hline
\end{tabular}

Fonte: adaptada de Porter (1986b) e De Toni e Forza (1992).

A Escola Nórdica (MELIN, 1992) pressupõe decisões seqüenciais ao longo da cadeia de valor, detalhando de forma mais específica as atividades de serviços, logística de distribuição e produção. Essa seqüência decorre da aprendizagem necessária à redução das distâncias psíquicas entre a empresa e o novo mercado.

No paradigma eclético de internacionalização, a cadeia de valor da corporação é avaliada de forma conjunta, definindo-se de forma integrada a coordenação e a configuração das atividades dispersas em diferentes mercados nacionais. Relacionando os estudos de Meijboom e Voss (1997) e De Toni e Forza (1992), pode-se identificar de forma analítica quanto as ações são internacionalizadas ao longo da CVO.

As atividades como $\mathrm{P} \& \mathrm{D}$, fornecimento, produção, distribuição e serviços variariam desde uma configuração e coordenação locais até coordenação e configuração globais. Por exemplo, a rede de fornecedores pode ser localizada no próprio país da empresa, ou seja, configurada e coordenada localmente, como sugerem Johanson e Vahlne (1977) e Andersen (1993) nos estágios iniciais. Por outro lado, pode ser estendida por vários países, onde componentes podem ser adquiridos com vantagens comparativas por meio de unidades externas de compras, ou seja, nesse caso essa atividade é configurada e coordenada 
globalmente. As atividades secundárias, como sistemas gerenciais e tecnologia, são influenciadas pelas decisões acerca de coordenação e configuração tomadas nas atividades primárias, por exemplo, P\&D. A configuração e coordenação de P\&D podem ser centralizadas ou dispersas, dependendo do tipo de tecnologia envolvida.

\section{Análise de Internacionalização Segundo a Ótica da Gestão de Operações}

Pode-se afirmar que a abordagem de internacionalização nos estudos da gestão de operações possuem foco maior em aspectos relacionados às escolhas estratégicas relativas à coordenação e configuração, sendo raros os que buscam analisar o tema de internacionalização dentro de uma abordagem de processo, como indica o trabalho de Prasad e Babbar (2000). Shi e Gregory (1998) mencionam padrões de configuração de manufatura internacional dentro de duas orientações principais: multidoméstica e global. Esses padrões de configuração estão relacionados a escolhas estratégicas que abrangem P\&D, produção, distribuição e serviços, envolvendo aspectos relativos à coordenação e interdependência das unidades da empresa.

Em artigo relacionado à logística de fornecimento como primeira atividade da CVO, Meijboon e Voss (1997) também seguem uma abordagem mais próxima das questões de escolhas estratégicas, abrangendo tanto aspectos relativos à coordenação quanto à configuração, como: suprimento internacional, gerência de demanda, aquisição global versus local e estratégias de produção.

Relativamente à atividade de produção propriamente dita, Ferdows (1989) argumenta que podem ser identificadas propostas distintas para a instalação de unidades de produção em diferentes países, seguindo também uma lógica de escolhas estratégicas sobre os elementos da estrutura organizacional ou de configuração. Os aspectos orientadores seriam o acesso a insumos mais baratos, utilização de recursos tecnológicos locais e proximidade de mercado. Em estudo posterior, Ferdows (1997) identifica dois vetores para a instalação de fábricas no exterior: nível de competência da unidade e razões estratégicas para instalação da unidade. DuBois e Oliff (1992) também seguem a mesma orientação de estruturação ou configuração das operações, ao identificarem quatro estratégias de configuração nas decisões de localização das unidades de produção internacionais.

Entre os diferentes estudos que enfocam a logística de distribuição internacional, Fawcett et al. (1997) enumeram os elementos relativos ao processo de desenvolvimento de competências internacionais em distribuição, embora não 
busquem identificar estágios ou fases desse processo. Por outro lado, Fawcett (1992) aborda, a partir da idéia de processo, a construção de logística estratégica dentro de uma abordagem global, destacando quais seriam os aspectos necessários para sua efetivação, como CDs e utilização de tecnologias de informação.

Na área de P\&D, Von Zedwitz e Gassmann (2002) identificam arquétipos relativos às decisões quanto à configuração de $\mathrm{P} \& \mathrm{D}$, sendo que duas seriam as forças que orientam a internacionalização dessa área: acesso à ciência e tecnologia local e acesso a mercados e clientes locais.

Envolvendo as atividades de serviços internacionalizados, raros são os artigos que abordam serviços como uma atividade agregada ao produto. Meijboom e Houtepen (2002) analisaram, em um estudo de caso, as possíveis configurações para provisão de um serviço global ou multidoméstico, enfatizando que as decisões se baseiam nos seguintes aspectos: intensidade do uso de mão-de-obra ou de envolvimento do consumidor no serviço, nível de utilização de recursos produtivos e intensidade das atividades de P\&D. Desse modo, também há uma abordagem de escolha estratégica, a partir de características específicas do serviço.

Conforme o exposto, entre os estudos sobre internacionalização de operações, poucos enfocam questões relativas ao processo de internacionalização propriamente dito, buscando identificar estágios ou etapas desse com maior detalhamento. Esses artigos, em sua maioria, limitam-se às decisões relativas principalmente à estrutura ou configuração. Isso pode ser explicado pela origem desses estudos. Em sua totalidade são estudos desenvolvidos por pesquisadores de países industrializados, onde as corporações mais competitivas seguem estratégias globais ou multidomésticas inseridas em mercados concorrenciais integrados globalmente.

Neste contexto, os desafios dessas corporações são relacionados com escolhas estratégicas do tipo estratégia global ou multidoméstica ou dispersão ou centralização, envolvendo tanto aspectos de configuração como coordenação. No caso brasileiro, as escolhas obviamente estão presentes; mas, como ainda a indústria nacional está em sua grande maioria em processo inicial de inserção em mercados internacionais, aspectos referentes a etapas ou estágios iniciais seriam válidos. Desse modo, os estudos da Escola Nórdica ainda forneceriam elementos de análise úteis, mesmo considerando-se todas as suas limitações.

\section{Estágios de Internacionalização}

A seguir, apresentam-se os estágios do processo de internacionalização de empresas com base no aumento da complexidade da configuração e coordenação das operações. 


\section{Estágio Inicial de Internacionalização}

No estágio inicial de internacionalização, o que equivaleria aos estágios 2 e 3 de Andersen (1993) e às etapas iniciais do estudo de Johanson e Vahlne (1977), há uma identificação de duas condições básicas: forte competitividade no país de origem e busca de menor distância psíquica no mercado alvo. Nesse caso, a análise de como empresas brasileiras estão buscando a internacionalização leva a alguns temas específicos como, por exemplo, a busca de inserção global de empresas que não são de grande porte. Yip et al. (2000) e Karagozoglu e Lindell (1998) apontam como dificuldades para as PME's com processos de internacionalização os seguintes aspectos: desconhecimento do desconhecido, escassez de recursos e de competências para enfrentar os problemas potenciais e dificuldades em obter informações sobre mercados internacionais, se comparados às grandes competidoras globais.

Whybark (1997) identifica como a razão para que as empresas norte-americanas sejam mais lentas em relação às empresas européias na busca inicial de internacionalização de suas operações, o grande mercado interno disponível a elas, o que não ocorreria no caso europeu. O estudo de Cyrino e Oliveira Junior (2002) sobre as dificuldades de empresas brasileiras em face da internacionalização revelou aspectos próximos: tamanho potencial do mercado interno brasileiro, impostos altos incidindo sobre as exportações, ausências de linhas de financiamento e barreiras comerciais nos mercados estrangeiros.

\section{Estágio Intermediário de Internacionalização}

Estudos específicos sobre esse estágio são difíceis de ser identificados. Podese considerar que nos estudos da Escola Nórdica, quando ocorrem as decisões de investimento em produção fora ou mesmo instalação de uma unidade de distribuição, a empresa se aproximaria desse estágio. Nesse momento, já existe algum conhecimento sobre o mercado alvo. Além das atividades de produção, distribuição e serviços, a empresa pode analisar outras decisões relacionadas às suas atividades, como a utilização de fornecedores estrangeiros para se expandir. Nesse estágio teriam igual importância elementos referentes ao estágio inicial, como aprendizagem, como referentes ao estágio avançado, em que as escolhas racionais preponderam.

\section{Estágio Avançado de Internacionalização}

Parte considerável dos estudos sobre internacionalização trata desse estágio, especialmente dentro do paradigma eclético. A decisão sobre a instalação de 
novas unidades produtivas e como serão configuradas as operações internacionais da empresa envolvem decisões de escala, mercado e custos envolvidos (BARRETO, 2002; KUTSCHKER; BÄURLE, 1997). Empresas em estágios avançados de internacionalização possuem conhecimento dos mercados e competidores globais. Esse conhecimento se estende também às demais atividades da cadeia de valor da empresa, envolvendo decisões referentes a fornecedores, tecnologia e P\&D. Estratégias global ou multidoméstica orientarão essas decisões, definindo aspectos relativos à configuração e coordenação de suas atividades (BARTLETT; GHOSHAL, 1992).

Simon (2003) apresenta algumas características de empresas alemãs globais que podem ser aplicadas ao contexto brasileiro. As pequenas e médias empresas - PME’s - alemãs, chamadas por ele de campeãs ocultas, “... são encontradas em mercados estreitos (e maduros) que não são por natureza globais, tendo elas de superar as barreiras nacionais” (p. 79). No caso brasileiro da Embraer, apesar de ser intensiva em tecnologia, essa se enquadra nos mercados de foco estreito, como aqueles mencionados pelo autor. De forma específica, Bartlett e Goshall (2000) salientam como um dos pontos importantes para alcançar competitividade global a busca de produtos de maior valor agregado e marcas globais.

\section{Método de Pesquisa}

O estudo foi conduzido por meio de quatro estudos de caso, buscando-se ressaltar características que permitissem a comparação entre esses (YIN, 2001). Estudos como Johanson e Vahlne (1977) e Yip et al. (2000) trazem a idéia do processo incremental de internacionalização que levariam à identificação de estágios de internacionalização. Por outro lado, na área de estratégia de operações, dois artigos clássicos apresentam propostas de estágios referentes à utilização de operações (HAYES; WHEELWRIGHT, 1985) e operações de serviços (CHASE; HAYES, 1991) como armas competitivas. Em ambos os artigos, os autores identificam padrões de decisões e ações, desde estágios pouco avançados até estágios mais avançados, denominados de World Class Manufacturing e World Class Service.

Os casos foram escolhidos seguindo duas orientações: nível de internacionalização e identificação prévia quanto à facilidade de acesso. Em relação ao primeiro aspecto, buscou-se identificar uma empresa iniciando sua estratégia de internacionalização, uma que já desenvolve atividades internacionais 
há mais tempo e duas que operam já segundo uma orientação próxima de corporação global. Desse modo, foram escolhidas as seguintes empresas: Muri Linhas de Montagem, iniciando a sua inserção internacional; Azaléia Calçados, já desenvolvendo atividades internacionais; e Marcopolo (ônibus) e Embraer (aviões), dentro do último caso. Apenas a Embraer não permitiu acesso direto, fazendo com que sua análise fosse realizada por meio de dados secundários (livros, revistas de negócios e website da empresa). Nas demais, foram entrevistados sócios (Muri) e diretores (Marcopolo e Azaléia). Em cada estudo de caso salientaram-se os aspectos principais relacionados à gestão da CVO e à busca de inserção internacional. As questões buscaram analisar como as atividades da CVO foram configuradas e coordenadas, a partir do início do processo de internacionalização da empresa.

A análise de cada caso segue a seqüência da CVO, não se tendo nenhuma pretensão que essa seja a seqüência temporal dos aspectos descritos. A pesquisa de campo foi realizada entre os anos de 2002 e 2003, possuindo uma orientação transversal preferencial na análise. Ainda assim, vale lembrar que Melin (1992) ressalta a importância de estudos longitudinais para estudos sobre o processo de internacionalização, a fim de revelar o dinamismo do processo. Nesse estudo, sem qualquer pretensão normativa ou determinista, busca-se descrever momentos diferentes relacionados a cada empresa, ressaltando possíveis decisões tomadas sobre a CVO. Todos os casos apresentados referem-se a empresas produtoras de bens de maior valor agregado, excluindo-se assim do estudo empresas que competem em mercados com produtos do tipo commodity. Seguiu-se essa orientação com o intuito de facilitar a comparação entre os casos.

\section{O Caso Muri}

A Muri é uma empresa situada em Porto Alegre, no Rio Grande do Sul, que produz sob encomenda linhas de montagem para empresas industriais dos setores automotivo, de eletrodomésticos e de componentes eletrônicos. Ela possui uma posição competitiva forte no mercado local, seu principal foco de atuação, e está buscando expandir-se no mercado global.

Seus clientes mais importantes são as principais empresas fornecedoras da indústria automobilística, como Delphi, Dana, Valeo, Behr, Brose, TRW e Eaton. A empresa começou a exportar a partir de um negócio inicial com a Dana dos Estados Unidos. Desde o início, esse negócio de US\$ 5 milhões já era parte considerável de seu faturamento, hoje da ordem de US\$ 15 milhões/ano. Em 1998, um dos objetivos principais era descobrir um sócio internacional para apoiar a estratégia de se tornar um competidor global. A razão para ter um sócio estrangeiro era ganhar conhecimento técnico nos negócios de linha de montagem. 
A formação e experiência de vida de um dos sócios nos Estados Unidos explicam de algum modo a razão da escolha preferencial por esse mercado para início de sua internacionalização.

\section{Fornecimento}

A empresa possui basicamente fornecedores locais, buscando integração com as empresas do mesmo porte e decidindo em questões de custos, desempenho de entrega e qualidade, quando há negociação com grandes empresas. Algumas exigências de qualidade de clientes externos têm levado a empresa a reavaliar seu nível atual de subcontratação, podendo verticalizar algumas partes do processo, a fim de ter maior controle sobre essas, como o caso da usinagem.

\section{Produção}

A política presente é de produção local, levando-se em conta as vantagens comparativas de custos operacionais. Mesmo que se consolidem os negócios no mercado internacional, ainda não há qualquer plano de produção em outra unidade fora do país.

\section{P\&D}

Depois de duas aproximações frustradas e tempo considerável, a empresa inicialmente consolidou a associação com uma empresa norte-americana. Em 2000, depois de dois anos de negociação, a Muri, finalmente, criou uma aliança com a Detroit Tool Industries, DTI. Para a Muri, a vantagem de desenvolver tal relação era agregar conhecimento comercial e técnico. Por outro lado, a DTI viu vantagem em ter a Muri como uma empresa de prestação de serviços para seus produtos no Brasil. A Muri e a DTI desenvolveram uma linha de montagem completa para uma das plantas da Eaton nos Estados Unidos, um dos fabricantes globais mais importantes na indústria de auto-peças. A partir desse negócio, desenvolveram-se outras vendas da empresa no mercado norteamericano.

\section{Logística de Distribuição e Serviços}

A empresa inicialmente utilizou a rede da parceira DTI. Em 2003, ao instalar unidade de comercialização própria em Detroit, Estados Unidos houve o rompimento com a parceira norte-americana. Essa unidade se prepara para ser uma unidade de prestação de serviços, sendo o segundo passo de expansão da CVO para outros mercados, considerando-se que vendas foi o primeiro. 
Sua estrutura de vendas está sendo desenvolvida paulatinamente e houve o deslocamento de um dos sócios para o mercado norte-americano com o objetivo de ganhar conhecimento sobre aquele mercado e desenvolver as vendas.

\section{O Caso Azaléia}

A Azaléia foi fundada em 1958 em Parobé, no Rio Grande do Sul. Suas atuais linhas de produtos são sapatos femininos e tênis. Em 2002, suas vendas foram de R \$ 681 milhões, representando as exportações 25\% desse total. Nos negócios internacionais, $90 \%$ corresponde aos sapatos femininos e $10 \%$ a tênis. A empresa possui uma participação crescente das exportações na sua receita total, conhece os seus competidores globais e busca posicionar-se estrategicamente no mercado global. Com base na linha de sapatos femininos, a empresa tem procurado usar estratégia distinta da tradicional utilizada pelo setor brasileiro nas exportações. Assim, as vendas são feitas por agentes de venda e atacadistas ao sistema varejista, sem a utilização de marca própria do fabricante, atuando exclusivamente em duas atividades da CVO: logística de fornecimento e produção. A Azaléia, buscando agregar mais valor, optou por desenvolver todas atividades da CVO, desde a criação do produto até a prestação de serviços e, ainda, de forma relevante, fazendo uso de marca própria.

\section{Fornecimento}

A empresa opera de forma verticalizada. Ela possui curtumes, empresas de componentes de calçados, chegando mesmo a investir em infra-estrutura, como uma usina hidrelétrica. Seu foco preferencial ainda é em fornecedores locais, porém já são importados tecidos para a fabricação de seus produtos.

\section{Produção}

Para atender os mercados interno e externo, a empresa opera diversas plantas industriais situadas no Rio Grande do Sul e no Nordeste. A localização das plantas no Brasil orienta-se, aos moldes do que ocorre com essa indústria mundialmente, pela conveniência do suprimento de matéria-prima e pelo fator mão-de-obra. No caso brasileiro, o último fator determina especialmente a posição em custo, ainda forte elemento na estratégia de exportação de nossas empresas, diferentemente do que ocorre na Itália, onde a mão-de-obra é elemento qualificador do produto, gerando uma oferta diferenciada. 


\section{P\&D}

No início, a empresa procurou vender as mesmas coleções desenvolvidas para o mercado doméstico. Como não teve êxito, passou a desenvolver os modelos segundo a preferência dos consumidores norte-americanos. O crescimento das vendas no mercado norte-americano resulta de diversos fatores. O Diretor Presidente da filial é norte-americano, com larga experiência no setor. Há um estilista local que, em conjunto com os estilistas da fábrica, prepara as coleções. Essas decisões evitam alguns dos erros apontados por Bartlett e Ghoshal (2000), como a não contratação de executivos e gerentes conhecedores de mercados locais.

\section{Logística de Distribuição e Serviços}

Para mais rápido atendimento dos pedidos, a empresa mantém estoque dos produtos com maior rotação e conecta-se a muitos clientes via sistema EDI Electronic Data Interchange. Seu centro de distribuição (CD) em St. Louis centraliza os pedidos e as distribuições no mercado norte-americano. A partir do CD em St. Louis, há uma gama de possibilidades de serviços oferecida para os clientes nos Estados Unidos. Entre esses está o atendimento de pedidos e reposições de estoque em quantidades mínimas. Além disso, opera com equipe de vendedores exclusivos e realiza anúncios em revistas destinadas ao público varejista.

Essas propostas competitivas, por envolverem a coordenação de atividades mundialmente dispersas e exigirem grandes investimentos em comunicação, são de difícil reprodução. A Azaléia tem procurado expandir-se internacionalmente nesse segmento com base em uma CVO verticalizada e com aumento gradativo de seu investimento promocional.

\section{O Caso Embraer}

No grupo de empresas brasileiras com foco global, a Embraer é uma das que possui melhor posição nos mercados globais. A empresa é especialista em aviões que operam regionalmente. Nos últimos anos, ela tem sido uma das maiores exportadoras brasileiras. A Embraer começou as vendas externas na América do Sul, especificamente para o Uruguai e o Chile nos anos 70 (SILVA, 1998). Depois de um crescimento lento das receitas externas, atualmente a participação de mercado corresponde a quase $50 \%$ do mercado global de aviões regionais, disputando com a empresa canadense Bombardier a liderança desse mercado. 
A Embraer oferece um produto mais barato com menor custo de manutenção, quando comparado ao do principal concorrente. A vantagem competitiva é claramente sustentada por uma posição de baixo custo. Não obstante, produtos da Embraer, especialmente aviões de ERJ, têm características inovadoras, seguindo uma proposta de BFC (Better, Faster, Cheaper) (OLIVEIRA; BERNARDES, 2002).

A configuração atual da empresa requer uma forte coordenação global das suas atividades, incluindo fornecimento, distribuição e serviços. Claramente, da atividade de P\&D até serviços, há a integração constante de conhecimento ao longo dos elos da CVO. Essa integração constante de conhecimento está baseada em aspectos como uma aliança na área de P\&D com uma empresa francesa, forte integração com seus fornecedores globais, proximidade de centros de pesquisa no Brasil e subsidiárias localizadas nos principais mercados focalizados. A competitividade global da Embraer está baseada, portanto, na integração global de todas as atividades ao longo da CVO.

\section{Fornecimento}

A empresa, desde que foi privatizada na década de 80 , tem desenvolvido uma ampla rede de fornecimento, inicialmente repassando parte de seus processos para ex-funcionários. Seu desafio desde então tem sido a coordenação dessa rede, o que tem tido efeito no lead-time de seus produtos, como no caso do Brasília, que saiu de 14 meses em 1995 para 6 meses em 1997. Grandes fornecedores globais têm dividido riscos em novos projetos e assumido até mesmo parte do financiamento das vendas. Entre esses podem ser citados GE, Grimes Aerospace, Honeywell e Kawasaki, entre outros (GHEMAWATH et al., 2000).

\section{Produção}

Historicamente tem produzido em uma única planta, levando-se em consideração o volume menor de produção. Atualmente, existem projetos de uma fábrica em Jacksonville, na Flórida e de uma joint venture na China, os quais indicariam novos objetivos em relação à função produção. No primeiro caso, a proximidade de seu principal mercado poderia ser a razão central para essa decisão. No caso chinês, a proximidade do maior mercado potencial poderia estar na essência da decisão.

\section{P\&D}

O lançamento de novos produtos tem orientado a seleção de fornecedores visando a aspectos relativos à rapidez e flexibilidade. A parceria tecnológica 
com a França é outro fato importante ocorrido nos últimos anos. O grupo que é integrado pela Aerospatiale / Matra e Dassault Aviation, detém 20\% do capital votante presentemente. Essa aliança é vista como a fonte de tecnologias para a Embraer, como no caso de sistemas inteligentes de defesa (GHEMAWATH et al., 2000).

\section{Logística de Distribuição e Serviços}

As primeiras unidades de serviços no exterior datam da década de 70 na França e Estados Unidos. Desde então, essas têm centralizado boa parte dos serviços de assistência técnica e reposição de peças dos aviões da empresa. Pelas características do produto, a distribuição ocorre de forma ampla nos mercados alvos da empresa. Essas subsidiárias vendem aviões e peças, oferecendo também serviços de manutenção corretiva e treinamento técnico. Os parceiros franceses têm também auxiliado a área de marketing e serviços da empresa em outros países. Para os executivos da empresa, o próximo passo é a China, de onde eles planejam expandir os negócios para os mercados asiáticos.

\section{O Caso Marcopolo}

A Marcopolo é uma empresa fabricante de ônibus, com sede em Caxias do Sul no Rio Grande do Sul, que opera unidades industriais no Brasil e no exterior, sob forma direta ou em parceria. Suas linhas de produtos são ônibus urbanos e rodoviários. A linha urbana de ônibus é exportada sob forma de partes e componentes, ocorrendo a sua montagem em unidades que a empresa tem no exterior. Nas vendas ao exterior, essas linhas são as mais significativas, com respectivamente $60 \%$ e 35\% do volume total. Em 1971, a empresa, para atender pedido de 2500 veículos, estabeleceu acordo com a Ensamblaje Superior da Venezuela. Ainda, durante as décadas de 70 e 80, foram realizados negócios semelhantes com Gana (1974), Equador (1975), Chile (1988) e Peru (1988).

A empresa opera plantas industriais com controle próprio no Brasil e em Portugal, e com sócios locais na Colômbia, África do Sul e México. Nesse último país, está associada a Daimler-Chrysler, que possui 23\% de participação no capital social. No mercado internacional, também deve ser destacada a sua associação com a Iveco, uma subsidiária da Fiat, para entrar no mercado da China. A planta de Portugal, além de atender ao mercado europeu, busca de captar os avanços tecnológicos que naquele continente são proeminentes. 


\section{Fornecimento}

A empresa utiliza basicamente fornecedores nacionais. A filial de Portugal, entretanto, dado o nível de qualidade dos fabricantes europeus de peças e componentes, realiza as suas compras naquele continente. As exigências de qualidade de diversos mercados globais fez com que a Marcopolo demandasse melhor qualificação dos fornecedores de peças e componentes.

\section{Produção}

Os ônibus rodoviários, com exceção de Portugal, e as peças e componentes dos ônibus urbanos são fabricados no Brasil. A centralização do processo de fabricação de partes e componentes e a descentralização da montagem permitem à empresa explorar as vantagens de escala. A localização das diversas plantas no exterior fez-se com base nos potenciais de mercado e na vantagem possibilitada pelo contorno de barreiras alfandegárias.

\section{P\&D}

A pesquisa de produto desenvolve-se predominantemente de forma centralizada. A planta de Portugal é fonte de tecnologia de ponta. Um dos resultados importantes da parceria com a Daimler-Chrysler no México foi o desenvolvimento de um novo ônibus, com inúmeros avanços sobre os existentes. Além do bom resultado em vendas, a empresa acumulou com esse projeto significativas competências que estão sendo transferidas agora para toda a linha de produtos, como o isolamento da carroceria.

\section{Logística de Distribuição e Serviços}

A grande capacidade produtiva e o processo de integração com os fornecedores possibilitam à empresa responder a grandes pedidos em prazos curtos e confiáveis e com produtos customizados. Para exemplificar, o prazo de fabricação que, na metade da década de 80 era de 30, é atualmente de 5 dias. Para ter preços competitivos internacionalmente é vital o domínio tecnológico possuído pela empresa de fabricar peças e componentes em um local e montá-los em outro. Com isso, hoje a empresa é capaz de distribuir seus produtos nos principais mercados alvo. A empresa é capaz de oferecer serviços de manutenção em qualquer parte do mundo dentro de 36 horas, mostrando uma prioridade clara no desenvolvimento desse tipo de competência.

A Marcopolo vem melhorando sua posição tanto na linha rodoviária como na linha de veículos urbanos. Na linha rodoviária, tem conseguido, de forma 
significativa, aumentar valor agregado de seus produtos, aproximando-os das marcas líderes mundiais. Na linha urbana, em que preço é elemento importante, uma posição vantajosa em custos vem sendo alcançada em decorrência de ações na área de produção e logística.

\section{Características dos Estágios Segundo os Casos Estudados}

Os casos estudados permitem alguns comentários preliminares. Inicialmente, é possível identificar decisões que incrementam a inserção internacional de todas as atividades da CVO, conforme a empresa desenvolve suas vendas e operações internacionalmente. Vale salientar que essas decisões são explicadas em parte pelas duas escolas de internacionalização destacadas no texto.

Nos estágios iniciais de internacionalização é possível identificar uma orientação preferencial pela aprendizagem, conforme pressupostos da Escola Nórdica. Os casos mostram que todas as empresas buscaram, de alguma forma, experiências iniciais com parceiros externos, a fim de ganhar gradativamente conhecimentos sobre o mercado pretendido. Nessa fase, os casos indicam a presença de questões como busca de menor distância psíquica, um dos aspectos centrais da Escola Nórdica. Para a Muri e Azaléia, o mercado norte-americano não era algo tão distante, até mesmo pela formação e experiências de vida dos sócios (Muri) e pelo setor competitivo a que a empresa pertence (Azaléia).

Nesse primeiro estágio, as decisões sobre internacionalização são referentes às atividades mais próximas ao consumidor final, iniciando-se por serviços e vendas, sendo seguidos por decisões de instalação de centros de distribuição. A partir do estágio inicial, os casos sugerem que as empresas começam a buscar decisões dentro de uma racionalidade econômica de forma crescente; por exemplo, quanto à instalação de novas unidades de produção. O processo de aprendizagem não se esgota, mas fatores econômicos serão fundamentais nesses estágios de internacionalização mais avançados.

Tais aspectos aparecem claramente no caso da Marcopolo e indicam que as novas unidades de produção resultam da contínua aprendizagem e da escolha com base em racionalidade econômica, considerando escala, custo e a configuração da CVO. Por outro lado, as plantas únicas da Muri e da Embraer, pelos menores volumes de produção e pelas suas histórias como empresas, situamse próximas a sua rede de fornecedores (Muri) ou fontes de mão-de-obra altamente capacitada (Embraer). O Quadro 1 sintetiza os principais aspectos referentes às CVO das empresas estudadas. 


\section{Quadro 1: Características da CVO das Empresas e Estágios de Internacionalização}

\begin{tabular}{|c|c|c|c|c|}
\hline \multirow{2}{*}{ Empresas } & \multirow{2}{*}{$\begin{array}{r}\text { Inicial } \\
\text { Muri } \\
\end{array}$} & \multirow{2}{*}{$\begin{array}{l}\text { Intermediário } \\
\text { Azaléia } \\
\end{array}$} & \multicolumn{2}{|c|}{ Avançado } \\
\hline & & & Marcopolo & Embraer \\
\hline Mercado foco & $\begin{array}{l}\text { Mercado norte- } \\
\text { americano }\end{array}$ & $\begin{array}{l}\text { Mercado norte- } \\
\text { americano }\end{array}$ & $\begin{array}{l}\text { Múltiplos } \\
\text { mercados }\end{array}$ & $\begin{array}{l}\text { Múltiplos } \\
\text { mercados }\end{array}$ \\
\hline Ênfase & Aprendizagem & Aprendizagem & $\begin{array}{l}\text { Racionalidade } \\
\text { econômica e } \\
\text { aprendizagem } \\
\end{array}$ & $\begin{array}{l}\text { Racionalidade } \\
\text { econômica e } \\
\text { aprendizagem } \\
\end{array}$ \\
\hline $\begin{array}{l}\text { Atividades da } \\
\text { CVO priorizadas }\end{array}$ & $\begin{array}{l}\text { Serviços e } \\
\text { distribuição }\end{array}$ & $\begin{array}{l}\text { Serviços e } \\
\text { distribuição }\end{array}$ & Todas & Todas \\
\hline \multicolumn{5}{|c|}{ Desenvolvimento da Cadeia de Valor de Operações } \\
\hline $\begin{array}{l}\text { Logística de } \\
\text { Fornecimento }\end{array}$ & Local & $\begin{array}{l}\text { Local com } \\
\text { expansão gradual }\end{array}$ & $\begin{array}{l}\text { Predominante- } \\
\text { mente local }\end{array}$ & Global \\
\hline Produção & $\begin{array}{l}\text { Totalmente } \\
\text { centralizada }\end{array}$ & $\begin{array}{l}\text { Várias plantas no } \\
\text { Brasil }\end{array}$ & $\begin{array}{l}\text { Avaliação } \\
\text { conjunta das } \\
\text { unidades } \\
\text { produtivas }\end{array}$ & $\begin{array}{l}\text { Centralizada, } \\
\text { com projetos } \\
\text { de expansão }\end{array}$ \\
\hline$P \& D$ & $\begin{array}{l}\text { Aprendizagem } \\
\text { sobre o mercado. } \\
\text { Adaptação do } \\
\text { produto de } \\
\text { acordo com } \\
\text { pedido de } \\
\text { cliente. } \\
\text { Definição inicial } \\
\text { dos parceiros. } \\
\end{array}$ & $\begin{array}{l}\text { Aprendizagem } \\
\text { sobre o mercado. } \\
\text { Produto } \\
\text { desenvolvido por } \\
\text { técnicos } \\
\text { brasileiros e dos } \\
\text { mercado alvo. }\end{array}$ & $\begin{array}{l}\text { Aprendizagem } \\
\text { de fontes } \\
\text { múltiplas: } \\
\text { associações, } \\
\text { plantas no } \\
\text { exterior e } \\
\text { diversos } \\
\text { mercados. }\end{array}$ & $\begin{array}{l}\text { Acesso a } \\
\text { conhecimento } \\
\text { de parceiros. } \\
\text { Competências } \\
\text { próprias já } \\
\text { desenvolvidas. }\end{array}$ \\
\hline $\begin{array}{l}\text { Logística de } \\
\text { Distribuição }\end{array}$ & $\begin{array}{l}\text { Em } \\
\text { desenvolvimento }\end{array}$ & $\begin{array}{l}\text { Em } \\
\text { desenvolvimento }\end{array}$ & $\begin{array}{l}\text { Já desenvolvidas, } \\
\text { melhorias } \\
\text { incrementais }\end{array}$ & $\begin{array}{l}\text { Já } \\
\text { desenvolvidas, } \\
\text { melhorias } \\
\text { incrementais } \\
\end{array}$ \\
\hline Serviços & $\begin{array}{l}\text { Limitado ao } \\
\text { mercado alvo }\end{array}$ & Em expansão & $\begin{array}{l}\text { Serviço } \\
\text { confiável nos } \\
\text { mercados } \\
\text { focalizados }\end{array}$ & $\begin{array}{l}\text { Rede Global } \\
\text { de Serviço }\end{array}$ \\
\hline
\end{tabular}

A logística de distribuição e os serviços apresentam características essencialmente de aprendizagem nos primeiros estágios de internacionalização. Ambas as atividades apresentam foco limitado no estágio inicial. No estágio intermediário, há uma cobertura geográfica mais ampla. No estágio avançado, as empresas estão representadas na maior parte dos mercados internacionais. 
Sinteticamente, as atividades de P\&D estão relacionadas, na primeira fase, a uma busca de parceiros externos, o que pode levar a uma cooperação de longo prazo. Assim, no estágio intermediário, já existem acordos de cooperação, mas não há ainda certeza quanto à sua continuidade no longo prazo. Isso fica particularmente mais claro no estágio avançado, quando as empresas pesquisadas desenvolvem cooperações mais contínuas ou efetivaram a participação de capital estrangeiro. Esse fato, porém, pode indicar que certo grau de dependência tecnológica ainda está presente, quando são comparados os casos pesquisados com empresas de países industrializados.

\section{Conclusões}

Este estudo permitiu identificar uma mudança a partir de abordagem local até uma posição global em todas atividades ao longo da CVO. No estágio inicial de internacionalização, a empresa busca a aprendizagem, envolvendo decisões nas atividades de serviços e logística de distribuição. Nos estágios mais avançados, as decisões são orientadas por escolhas estratégicas baseadas em escala, mercados e custos, envolvendo logicamente a aprendizagem necessária e a expansão geográfica das atividades da CVO. Portanto, para estágios iniciais de internacionalização de empresas brasileiras, pressupostos da Escola Nórdica ainda são úteis. Para os estágios mais avançados, não são identificados padrões únicos quanto às decisões sobre configuração e coordenação.

Especificamente no caso de $\mathrm{P} \& \mathrm{D}$, a procura de sócios externos pode revelar certo grau de dependência tecnológica das empresas brasileiras. Provavelmente, esse aspecto deve constituir o principal desafio para a sustentação de uma competitividade em níveis globais, especialmente em mercados com produtos de maior valor agregado. Pesquisas futuras poderiam estudar outros casos de empresas brasileiras que estão buscando aumento de sua inserção nos mercados internacionais com características distintas das estudadas, como as fabricantes de produtos quase commodities.

A principal limitação deste trabalho é quanto à estratégia de pesquisa utilizada - o método do caso com corte transversal. A fim de se buscar maior possibilidade de generalização, estudos futuros poderão ser realizados com base em amostras mais amplas. Por outro lado, novos estudos de caso longitudinais poderiam reforçar a proposta de estágios de internacionalização. Um limitante adicional deste trabalho diz respeito à diversidade de setores pesquisados. Se, por um lado, isso possibilitou uma visão mais ampla, por outro não conduziu ao aprofundamento do conhecimento de cada setor. Como dimensão positiva, tem-se a emergência de 
novas proposições para investigação relacionadas à competitividade global. Entre estas, pode-se destacar o papel do conhecimento organizacional, a criação de canais de distribuição e o desenvolvimento de marcas globais brasileiras.

\section{Artigo recebido em 03.12.2003. Aprovado em 10.09.2004.}

\section{RefERÊnCIAS Bibliográficas}

ANDERSEN, O.

On the internationalization process of firms: a critical analysis. Journal of International Business Studies. Washington, v. 24, n. 2, p. 209-231, second quarter 1993.

\section{ANDERSON, E.;}

GATIGNON, $\mathrm{H}$.

Modes of entry: a transactions cost analysis and propositions. Journal of International Business Studies. Washington, v. 17, n. 3, p. 1-26, fall 1986.

\section{BJÖRKMAN, I.;}

FORGSGREN, $M$.

Nordic international business research - a review and its development. International Studies of Management \& Organization. White Plains, v. 30, n. 9, p. 6-27, spring 2000.

\section{BARRETTO, A.}

A internacionalização da firma sob o enfoque dos custos de transação. In: ROCHA, A. A internacionalização das empresas brasileiras: estudos de gestão internacional. 1. ed. Rio de Janeiro: Mauad, 2002.

BARTLETT, C.A.;

GHOSHAL, S.

Gerenciando empresas no exterior: a solução transnacional. 1. ed. São Paulo: Makron, 1992.

Going global: lessons from late movers. Harvard Business Review. Watertown, v. 78, n. 2, p. 132-143, Mar./Apr. 2000.

CHASE, R. B.;

HAYES, R. H.

Beefing up operations in service firms. Sloan Management Review. Estados Unidos, v. 33, n. 1, p. 15-26, fall 1991.

CYRINO, A. C.;

OLIVEIRA JUNIOR, M. M.

Global players research investigation on the internationalization processes of companies in Brazil. Nova Lima: Fundação Dom Cabral, 2002. Caderno de Idéias, CIO224.

DE TONI, A.;

FORZA, R. F.

Manufacturing strategy in global markets: an operations management model. International Journal of Operations \& Production Management. Bradford, v. 12, n. 4, p. 7-18, 1992. 
DUBOIS, F. L.;

OLIFF, M. D.

International manufacturing configuration and competitive priorities. In: VOSS, C. A. Manufacturing strategy - process and content. 1. ed. Londres: Chapman Hall, 1992.

\section{DUNNING J. H.}

The eclectic paradigm of international production: a restatement and some possible extensions. Journal of International Business. Abington, $\mathrm{v}$. 8, n. 1, p. 1-31, spring 1988.

\section{ECONOMIST, THE.}

Who dares you. London, v. 356, n. 8189, p. 86-91, 23 sept. 2000. Disponível em: <http://www.economist.com>. Acesso em: 15 Mar. 2001.

\section{EXAME, Revista.}

Corra, ainda dá tempo, 16 maio 2001.

Disponível em: <http:// www.portalexame.abril.com.br>. Acesso em: 22 June 2001.

FAWCETT, S. E.

Strategic logistics in co-ordinated global manufacturing success. International Journal of Production Research. Abingdon, v. 30, n. 4, p. 1081-1099, Apr. 1992.

FAWCETT, S. E.;

CALANTONE, R.;

SMITH, S. R.

Delivery capability and firm performance in international operations. International Journal of Production Economics. Amsterdam, v. 51, n. 3, p. 191-204. 15 Sept. 1997.
FERDOWS, K.

Mapping international manufacturing networks. In: FERDOWS, K. Managing international manufacturing. 4th ed. New York: North Holland, 1989.

Making the most of foreign factories, Harvard Business Review. Watertown, v. 75, n. 2, p. 73-89, Mar./ Apr. 1997.

\section{GHEMAWAT, P.;}

HERRERO, G. A.;

MONTEIRO, L. F.

Embraer: the global leader in regional jets. Caso para Ensino, Harvard Business School. Watertown, v. 1, n. 1 p. 1-21, July 2000.

HAYES, R. H.;

WHEELWRIGHT, R.

Competing through manufacturing, Harvard Business Review. Watertown, v. 63, n. 1, p. 99-109, Jan./ Feb. 1985.

HILAL, A.;

HEMAIS, C. A.

Da escola de Uppsala à escola nórdica de negócios internacionais: uma visão analítica. In: ENCONTRO NACIONAL DAANPAD, 25., 2001, Campinas, SP, Anais... Campinas, SP: ANPAD, 2001.

HILL, C. W. L.;

HWANG, P.;

KIM, W. C.

An eclectric theory of the choice of international entry mode, Strategic Management Journal. Chichester, v. 11, n. 2, p. 117-128, Feb. 1990. 
JOHANSON, J.;

VAHLNE, J.E.

The internationalization process of the firm - a model of knowledge development and increasing foreign market commitments, Journal of International Business Studies. Atlanta, v. 8, n. 1, p. 23-32, spring 1977.

KARAGOZOGLU, N.;

\section{LINDELL, $M$.}

Internalization of small and mediumsized technology based firms: an exploratory study. Journal of Small Business Management, Milwaukee, v. 36, n. 1, p. 44-59, Jan. 1998.

\section{KUTSCHKER, M.;}

\section{BÄURLE, I.}

Three + one: multidimensional strategy of internationalization, Management International Review. Wiesbaden, v. 37, n. 2, p. 103-125, second quarter 1997.

\section{MEIJBOOM, B.;}

\section{VOSS, B.}

International manufacturing and location decisions: balancing configuration and coordination aspects, International Journal of Operations \& Production Management. Bradford, v. 17, n. 8, p. 790-805, 1997.

MEIJBOOM, B.;

\section{HOUTEPEN, $M$.}

Structuring international service operations: a theoretical framework and a case study in the IT-sector, International Journal of Operations \& Production Management. Bradford, v. 22, n. 7/8, p. 824-842, 2002.
MELIN, L.

Internationalization as a strategy process, Strategic Management Journal. Chichester, v. 13, Special Issue, p. 99-118, winter 1992.

OLIVEIRA, L. G;

BERNARDES, R.

O desenvolvimento do design em sistemas complexos na indústria aeronáutica: o caso de gestão integrada de projetos aplicada ao programa ERJ-170/190. In: ENCONTRO NACIONAL DA ANPAD, 26., 2002, Salvador. Anais... Salvador: ANPAD, 2002.

PORTER, M. E.

Competition on global markets. 1. ed. Boston, Massachusetts: Harvard Business Press, 1986a.

Vantagem competitiva: criando e sustentando um desempenho superior. 1. ed. Rio de Janeiro: Campus, 1986b.

PRASAD, S.;

BABBAR, $S$.

International operations management research, Journal of Operations Management. Columbia, v. 18, n. 2, p. 209-247, Feb. 2000.

\section{SHI, Y.;}

\section{GREGORY,M.}

International manufacturing networks - to develop global competitive capabilities, Journal of Operations Management. Columbia, v. 16, n. 2/3, p. 195-214, May 1998.

\section{SIMON, H.}

Campeãs Ocultas. 1. ed. Porto Alegre: Bookman, 2003. 
SILVA, O. S.

A decolagem de um sonho: a história da criação da EMBRAER. 1. ed. São Paulo: Lemos, 1998.

WHYBARK, D. C.

Does international operations management need a separate perspective? Production and Operations Management. Muncie, v. 6, n. 2, p. 122-131, summer 1997.

YIN, R. K.

Estudo de caso: planejamento e métodos. 2. ed. Porto Alegre: Bookman, 2001.
YIP, G. S.;

BISCARRI, J. G.;

MONTI, J.A.

The role of the internationalization process in the performance of newly internationalizing firms, Journal of International Marketing. Chicago, v. 8, n. 3, p. 10-35, 2000.

VON ZEDTWITZ, M.; GASSMANN, O.

Market versus drive in $R \& D$ internationalization: four different patterns of managing research and development, Research Policy. Amsterdam, v. 31, n. 4, p. 569-588, May 2002. 